\title{
Numerical Approximation Based on the Bernouli Polynomials for Solving Volterra Integro-Differential Equations of High Order
}

\author{
Mashallah Matinfar*, Hamideh Abdollahi Lashaki; \\ University of Mazandaran \\ Mojgan Akbari, University of Guilan
}

Received: 30 Jan 2017

Revised: 23 Dec 2017

\begin{abstract}
In this article, an applied matrix method, which is based on Bernouli Polynomials, has been presented to find approximate solutions of high order Volterra integro-differential equations. Through utilizing this approach, the proposed equations reduce to a system of algebric equations with unknown Bernouli coefficients. A comparison of Bernouli matrix method solutions with the results of the other numerical methods has been carried out, which shows that the Bernouli matrix metod solutions are more accurate in comparison with the other methods.
\end{abstract}

Keywords: Integro-differential equations, Bernouli polynomials, Operational matrix.

\section{Introduction}

Integro-differential equations are a adaptable mathematical implement for symbolizing physical problems. A review of the related literature reveals that, they have been very popular among researchers in the mathematical modelling of physical phenomenon as gravitation, electrostatics, etc. It is also famous that initial-value and boundary-value problems of differential equations can often be converted into integral equations and there are usually considerable advantages employing this conversion. Among these equations, Volterra integro-differential equations is derived from various applications, like engineering, biology, etc (see [8], [11] and the references therein).

Polynomial series have gained significant attention in dealing with various problems of differential, integral and integro-differential equations. Since polynomials can easily be defined, they are very useful mathematical tools which can be calculated quickly on computer systems and represent a great variety of functions. It is rather easy to differentiate

\footnotetext{
*Corresponding author: m.matinfar@umz.ac.ir
} 
and integrate them, and they can be pieced together to form spline curves that can precisely approximate any function. Also, the main feature of this method technique is that it reduces complex problems to those simpler problems of solving a system of algebraic equations, thus they can greatly simplify the problems.

Bernouli polynomials play a main role in a variety of expansions and approximation formulas. These formulas can be very useful not only in analytic theory of numbers, but also in classical and numerical analysis. The Bernoulli polynomials and numbers have been generalized by Norlund [18] to the Bernoulli polynomials and numbers of higher order. Also, Vandiver in [24] generalized the Bernoulli numbers. Analogous polynomials and sets of numbers have been defined from time to time, witness the Euler polynomials and numbers and the so-called Bernoulli polynomials of the second kind. These polynomials can be defined by various methods [13], [14], [15], [12], [20], [17].

This paper concerns the following high order volterra integro-differential equation in the form

$$
\sum_{j=0}^{m} c_{j} y^{j}(x)=f(x)+\int_{0}^{x} k(x, s) y(s) d s, \quad 0 \leq x<1
$$

with initial condition $\mathrm{y}^{\mathrm{j}}(0)=\alpha_{\mathrm{j}}, \quad \mathrm{j}=0,1, \ldots, \mathrm{m}-1$.

where, $y(x)$ and $f(x)$ are continuous differentiability functions of the desired order and $\mathrm{k}(\mathrm{x}, \mathrm{s})$ is a continuous differentiability of the desired order and seprable kernel and $c_{j}$ 's are constant coefficiens and $y^{j}(x)=\frac{d^{j}}{d x^{j}} y(x)$.

This article is classified as follows: in section 2, we have presented the elementary possessions of the Bernoulli polynomials. Section 3 is applied to the approximation of functions by Bernouli polynomials. In section 4, operational matrix is presented. In section 5, the process of the method is explained and in section 6 convergence of method is analysed. Finally, in section 7 a comparison of the numerical solutions is made with some exact or approximate solutions in order to assess the precision of the suggested method.

\section{Bernouli Polynomials}

The Bernouli polynomials of order $\mathrm{m}$, are defined in [12] by

$$
\mathrm{B}_{\mathrm{m}}(\mathrm{x})=\sum_{\mathrm{k}=0}^{\mathrm{m}}\left(\begin{array}{c}
\mathrm{m} \\
\mathrm{k}
\end{array}\right) \beta_{\mathrm{k}} \mathrm{x}^{\mathrm{m}-\mathrm{k}},
$$


where, $\beta_{\mathrm{k}}, \mathrm{k}=0,1, \ldots, \mathrm{m}$ are Bernouli numbers. These numbers are a sequence of signed rational numbers, which are obtained from the series expansion of trigonometric functions [3] and can be defined by

$$
\frac{\mathrm{t}}{\mathrm{e}^{\mathrm{t}-1}}=\sum_{\mathrm{n}=0}^{\infty} \beta_{\mathrm{n}} \frac{\mathrm{t}^{\mathrm{n}}}{\mathrm{n} !}
$$

The first few Bernouli numbers are

$$
\beta_{0}=1, \beta_{1}=\frac{-1}{2}, \beta_{2}=\frac{1}{6}, \beta_{4}=\frac{-1}{30},
$$

with $\beta_{2 \mathrm{k}+1}=0, \mathrm{k}=1,2,3, \ldots$ The first few Bernouli Polynomials are

$$
\mathrm{B}_{0}(\mathrm{x})=1, \mathrm{~B}_{1}(\mathrm{x})=\mathrm{x}-\frac{1}{2}, \mathrm{~B}_{2}(\mathrm{x})=\mathrm{x}^{2}-\mathrm{x}+\frac{1}{6}, \mathrm{~B}_{3}(\mathrm{x})=\mathrm{x}^{3}-\frac{3}{2} \mathrm{x}^{2}+\frac{1}{2} \mathrm{x},
$$

The following properties apply Bernouli Polynomials [7,16]

$$
\begin{aligned}
& \mathrm{B}_{\mathrm{m}}(0)=\beta_{\mathrm{m}^{\prime}} \mathrm{m} \geq 0 \\
& \int_{\mathrm{a}}^{\mathrm{x}} \mathrm{B}_{\mathrm{m}}(\mathrm{t}) \mathrm{dt}=\frac{\mathrm{B}_{\mathrm{m}+1}(\mathrm{x})-\mathrm{B}_{\mathrm{m}+1}(\mathrm{a})}{\mathrm{m}+1} \\
& \int_{0}^{1} \mathrm{~B}_{\mathrm{n}}(\mathrm{t}) \mathrm{B}_{\mathrm{m}}(\mathrm{t}) \mathrm{dt}=(-1)^{\mathrm{n}-1} \frac{\mathrm{m} ! \mathrm{n} !}{(\mathrm{m}+\mathrm{n}) !}, \mathrm{m}, \mathrm{n} \geq 1 \\
& \sum_{\mathrm{k}=0}^{\mathrm{n}} \mathrm{B}_{\mathrm{k}}(\mathrm{t})=(\mathrm{n}+1) \mathrm{t}^{\mathrm{n}}
\end{aligned}
$$

It can be easily illustrated that any given polynomial of degree $\mathrm{n}$ can be expanded with regard to linear combination of the basis function

$$
\mathrm{p}(\mathrm{x})=\sum_{\mathrm{i}=0}^{\mathrm{n}} \mathrm{c}_{\mathrm{i}} \mathrm{B}_{\mathrm{i}}(\mathrm{x})=\mathrm{C}^{\mathrm{T}} \mathrm{B}(\mathrm{x})
$$

where $\mathrm{C}$ and $\mathrm{B}(\mathrm{x})$ are $(\mathrm{n}+1) \times 1$ vectors given by

$$
\mathrm{C}=\left[\mathrm{c}_{0}, \mathrm{c}_{1}, \ldots, \mathrm{c}_{\mathrm{n}}\right]^{\mathrm{T}}, \mathrm{B}(\mathrm{x})=\left[\mathrm{B}_{0}(\mathrm{x}), \mathrm{B}_{1}(\mathrm{x}), \ldots, \mathrm{B}_{\mathrm{n}}(\mathrm{x})\right]^{\mathrm{T}}
$$

for each $\mathrm{i}=0,1, . ., \mathrm{n}$ the following matrix form can be obtained:

$$
B_{i}(x)=\left(\begin{array}{l}
i \\
i
\end{array}\right) B_{i}+\left(\begin{array}{c}
i \\
i-1
\end{array}\right) B_{i-1} x+\cdots+\left(\begin{array}{l}
i \\
1
\end{array}\right) B_{1} x^{i-1}+\left(\begin{array}{l}
i \\
0
\end{array}\right) B_{0} x^{i},
$$

then

$$
\mathrm{B}_{\mathrm{i}}(\mathrm{x})=\mathrm{M}_{\mathrm{i}} \mathrm{T}(\mathrm{x})
$$

where $\mathrm{T}(\mathrm{x})=\left[\begin{array}{lllll}1 & \mathrm{x} & \mathrm{x}^{2} & \ldots & \mathrm{x}^{\mathrm{n}}\end{array}\right]^{\mathrm{T}}$, and

$$
\left.M_{i}=\left[\begin{array}{l}
i \\
i
\end{array}\right) B_{i}\left(\begin{array}{c}
i \\
i-1
\end{array}\right) B_{i-1}\left(\begin{array}{c}
i \\
i-2
\end{array}\right) B_{i-2} \cdots\left(\begin{array}{l}
i \\
1
\end{array}\right) B_{1}\left(\begin{array}{l}
i \\
0
\end{array}\right) B_{0}\right],
$$

Now, we can expand the matrix $\mathrm{B}(\mathrm{x})$ as

$$
B(x)=\left[B_{0}(x), B_{1}(x), \ldots, B_{n}(x)\right]^{T}=\left[M_{0} T(x), M_{1} T(x), \ldots, M_{n} T(x)\right]^{T}
$$




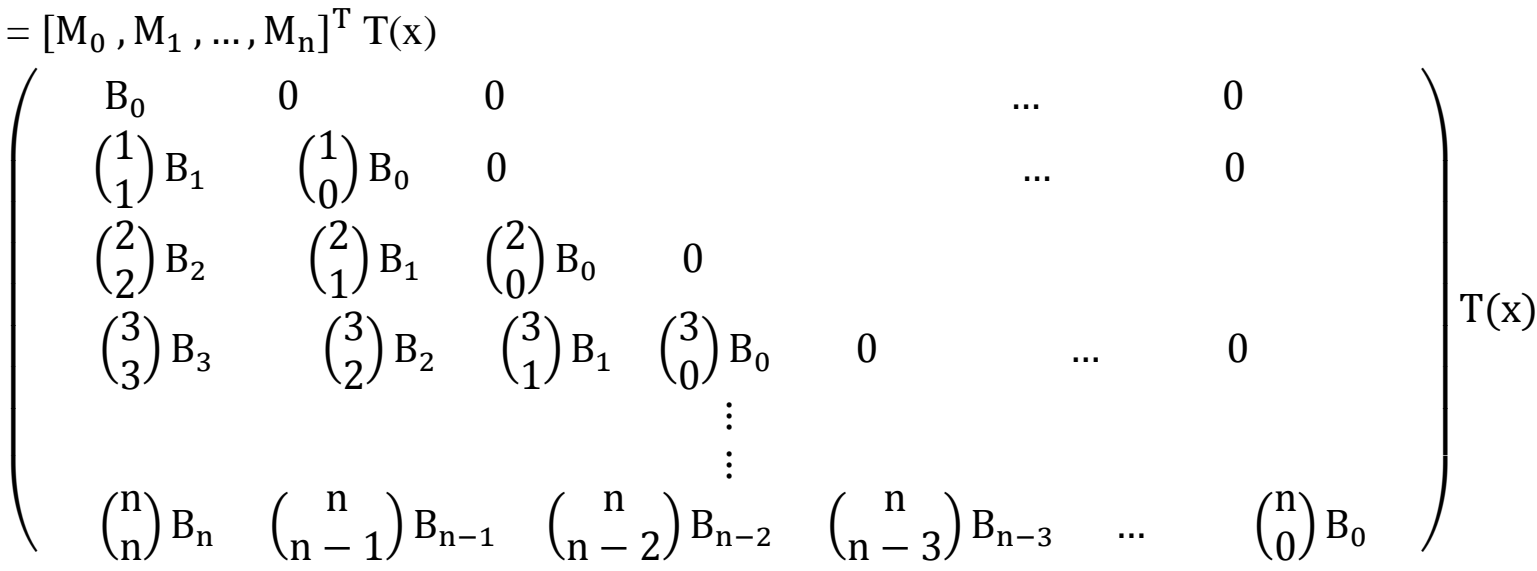

then, we have

$$
\mathrm{B}(\mathrm{x})=\mathrm{MT}(\mathrm{x}),
$$

where $M$ is a lower triangular $(n+1)(n+1)$ matrix and $\operatorname{det}(M)=1$, so $M$ is an invertible matrix.

On the other hand by using Eq. (6), we have

$$
\begin{gathered}
\sum_{\mathrm{k}=0}^{\mathrm{n}+1} \mathrm{~B}_{\mathrm{k}}(\mathrm{x})=(\mathrm{n}+1) \mathrm{x}^{\mathrm{n}}, \\
\mathrm{QB}(\mathrm{x})=\mathrm{T}(\mathrm{x}) \Rightarrow \mathrm{B}(\mathrm{x})=\mathrm{Q}^{-1} \mathrm{~T}(\mathrm{x}),
\end{gathered}
$$

where $\mathrm{Q}$ is a lower triangular $(\mathrm{n}+1)(\mathrm{n}+1)$ matrix and $\operatorname{det}(\mathrm{Q})=1$, so $\mathrm{Q}$ is an invertible matrix.

Then from (9), (10), we have

$$
\mathrm{Q}^{-1}=\mathrm{M}
$$

\section{Approximation of functions}

Suppose that $\mathrm{H}=\mathrm{L}^{2}[0,1]$ and $\left\{\mathrm{B}_{0}(\mathrm{x}), \mathrm{B}_{1}(\mathrm{x}), \ldots, \mathrm{B}_{\mathrm{N}}(\mathrm{x})\right\} \subset \mathrm{H}$ be the set of Bernoulli polynomials and

$$
\mathrm{Y}=\operatorname{span}\left\{\mathrm{B}_{0}(\mathrm{x}), \mathrm{B}_{1}(\mathrm{x}), \ldots, \mathrm{B}_{\mathrm{N}}(\mathrm{x})\right\}
$$

and $\mathrm{f}$ be any member in $\mathrm{H}$. Since $\mathrm{Y}$ is a finite dimensional vector space, $\mathrm{f}$ has the unique best approximation out of $\mathrm{Y}$ such as $\hat{\mathrm{f}}$, that is

$$
\forall \mathrm{y} \in \mathrm{Y}, \quad\|\mathrm{f}-\hat{\mathrm{f}}\| \leq\|\mathrm{f}-\mathrm{y}\|,
$$

Since $\hat{f} \in \mathrm{Y}$, there exists the unique coefficients $\mathrm{f}_{0}, \mathrm{f}_{1}, \ldots, \mathrm{f}_{\mathrm{N}}$ such that

$$
f \approx \hat{\mathrm{f}}=\sum_{n=0}^{N} f_{n} B_{n}(x)=F^{T} B(x)
$$


which

$$
B^{T}(\mathrm{x})=\left[\mathrm{B}_{0}(\mathrm{x}), \mathrm{B}_{1}(\mathrm{x}), \ldots, \mathrm{B}_{\mathrm{N}}(\mathrm{x})\right], F^{T}=\left[f_{0}, f_{1}, \ldots, f_{n}\right]
$$

Corollary 3.1. Suppose that $\mathrm{f}$ be an arbitrary function and also is approximated by the truncated Bernoulli series as $\sum_{i=0}^{N} f_{i} B_{i}(x)$ then the coefficients $f_{i}$ can be computed from the following formula

$$
f_{i}=\frac{\int_{0}^{1} f^{(i)}(x) d x}{i !}
$$

which $\mathrm{i}=1, \ldots, \mathrm{N}$.

Corollary 3.2. Suppose that $\mathrm{K}(\mathrm{x}, \mathrm{s}) \in \mathrm{H} \times \mathrm{H}=\mathrm{L}^{2}[0,1] \times \mathrm{L}^{2}[0,1]$ be an arbitrary function and also is approximated by the two variable truncated Bernoulli series

$$
\sum_{m=0}^{N} \sum_{n=0}^{N} k_{m, n} B_{m}(x) B_{n}(s),
$$

then the coefficients $\mathrm{k}_{\mathrm{m}, \mathrm{n}}$ can be computed from the following relation

$$
\mathrm{k}_{\mathrm{m}, \mathrm{n}}=\frac{1}{\mathrm{~m} ! \mathrm{n} !} \int_{0}^{1} \int_{0}^{1} \frac{\partial^{\mathrm{m}+\mathrm{n}} \mathrm{k}(\mathrm{x}, \mathrm{s})}{\partial \mathrm{x}^{\mathrm{m}} \partial \mathrm{x}^{\mathrm{n}}} \mathrm{dxds}, \mathrm{m}, \mathrm{n}=0,1, \ldots, \mathrm{N}
$$

or

$$
\mathrm{k}(\mathrm{x}, \mathrm{s}) \simeq B^{T}(\mathrm{x}) \mathrm{KB}(\mathrm{s}),
$$

which $\mathrm{K}=\left(\mathrm{k}_{\mathrm{m}, \mathrm{n}}\right)_{(\mathrm{N}+1) \times(\mathrm{N}+1)}, \mathrm{m}, \mathrm{n}=0,1, . ., \mathrm{N}$.

\section{Opeartioanal matrix of integration}

Theorem 4.1. For integration of the vector $B(t)$ defined in Eq. (11) we have the following formula

$$
\int_{0}^{\mathrm{x}} \mathrm{B}(\mathrm{t}) \mathrm{dt} \cong \mathrm{PB}(\mathrm{x})
$$

which $\mathrm{P}$ is the $(\mathrm{N}+1) \times(\mathrm{N}+1)$ operational matrix of integration, which $\mathrm{P}=\mathrm{UQ}$ where $\mathrm{U}=\left[\mathrm{U}_{1}, \mathrm{U}_{2}, \ldots, \mathrm{U}_{\mathrm{n}}, \Xi^{\mathrm{T}} \mathrm{M}\right]^{\mathrm{T}}$

where

$$
\mathrm{U}_{\mathrm{i}}=\left[\begin{array}{ll}
\left.0 \frac{1}{\mathrm{i}}\left(\begin{array}{c}
\mathrm{i} \\
\mathrm{i}-1
\end{array}\right) \mathrm{B}_{\mathrm{i}-1} \frac{1}{\mathrm{i}}\left(\begin{array}{c}
\mathrm{i} \\
\mathrm{i}-2
\end{array}\right) \mathrm{B}_{\mathrm{i}-2} \quad \ldots \frac{1}{\mathrm{i}}\left(\begin{array}{l}
\mathrm{i} \\
1
\end{array}\right) \mathrm{B}_{1} \frac{1}{\mathrm{i}} \mathrm{B}_{0} \ldots\right]
\end{array}\right]
$$

and $\Xi=\left[c_{1}, c_{2}, \ldots, c_{n}\right]^{T}$ which $\frac{B_{N+1}(x)-B_{N}}{N+1} \cong \Xi^{T} B(x), \Xi$ can be obtained by (12). 
The operational matrix of integration, $\mathrm{P}$, is a sparse matrix, which is one of the advantages of using Bernouli polynomials for solving equations. For example, for $\mathrm{N}=3$, $\mathrm{P}$ is

$$
\left[\begin{array}{llll}
\frac{1}{2} & 1 & 0 & 0 \\
\frac{-1}{12} & 0 & \frac{1}{2} & 0 \\
0 & 0 & 0 & \frac{1}{3} \\
\frac{1}{120} & 0 & \frac{1}{14} & 0
\end{array}\right]
$$

And, it can be seen by computing the operation matrix for higher degrees, as the $\mathrm{N}$ increases, the matrix becomes more sparse.

\section{Description of Bernouli matrix method}

For solving the proposed Volterra integro-differential equations, first, we can approximate the unknown function $y^{m}(\mathrm{x})$ by Bernouli matrix as

$$
y^{m}(\mathrm{x})=\mathrm{A}^{\mathrm{T}} \mathrm{B}_{\mathrm{m}}(\mathrm{x}) \text {, }
$$

which $\mathrm{A}^{\mathrm{T}}=\left[\mathrm{a}_{0}, \mathrm{a}_{1}, \ldots, \mathrm{a}_{\mathrm{N}}\right]$ is the unknown vector. By integrating Eq. (16), we have

$$
y_{i}(x)=\sum_{j=0}^{i} A_{j}^{T} P^{j} B(x),
$$

which $A_{j}^{T}=\left[\alpha_{j}, 0, \ldots, 0\right], j=0,1, \ldots, m-1$.

Now, by (11), (14), (16), we approximate $\mathrm{f}(\mathrm{x})$ and $\mathrm{k}(\mathrm{x}, \mathrm{s})$ by Bernouli polynomials and by replacing them and (16), (17) in the Eq. (1), we have

$$
\sum_{\mathrm{i}=0}^{\mathrm{m}} \sum_{\mathrm{j}=0}^{\mathrm{i}} \mathrm{A}_{\mathrm{j}}^{\mathrm{T}} \mathrm{P}^{\mathrm{j}} \mathrm{B}(\mathrm{x})=\mathrm{F}^{\mathrm{T}} \mathrm{B}(\mathrm{x})+\mathrm{B}(\mathrm{x}) \mathrm{K}\left(\int_{0}^{\mathrm{x}} \mathrm{B}^{\mathrm{T}}(\mathrm{s}) \mathrm{B}(\mathrm{s}) \mathrm{ds}\right) \sum_{\mathrm{j}=0}^{\mathrm{m}} \mathrm{P}^{\prime} \mathrm{j} \mathrm{A}_{\mathrm{j}}
$$

Now we collocate (18) in $\mathrm{N}+1$ nodes

$$
t_{i}=\frac{2 i-1}{2(N+1)}, i=1,2, \ldots, N+1
$$

then we have a system of linear algebric equations of $(\mathrm{N}+1) \times(\mathrm{N}+1)$ degree, with unknown vector $A_{m}$, by solving this linear system, we find $A_{m}$, and can approximate the solution of equation (1) as follows 


$$
y(x)=\sum_{j=0}^{m} A_{j}^{T} P^{j} B(x)
$$

\section{Convergence Analysis}

In this section, an error analysis will be implied to apparently explain the convergence of the mentioned method. Assume that we approximate the function $\mathrm{f}$ on the interval $[0,1]$ by Bernoulli polynomials as argued in Corollary 3.1. Then the coefficients $f_{n}$ decays as follows $f_{n} \leq \frac{F_{n}}{n !}$, where $f_{n}$ denotes the maximum of $f_{n}$ in the interval [0,1]. The above Corollary implies that Bernoulli coefficients are decayed rapidly as decreasing of $n$. Now we have the following theorem.

Theorem 6.1. [1] Suppose that $f(x)$ be an enough smooth function in the interval $[0,1]$ and be approximated by Bernoulli polynomials as done in Corollary 3.1. With more details assume that $P_{N}[f](x)$ is the approximate polynomial of $f(x)$ in terms of Bernoulli polynomials and $\mathrm{R}_{\mathrm{N}}[\mathrm{g}](\mathrm{x})$ is the remainder term. Then, the associated formulas are stated as follows

$$
\begin{gathered}
f(x)=P_{N}[f](x)+R_{N}[f](x) \\
P_{N}[f](x)=\int_{0}^{1} f(x) d x+\sum_{j=1}^{N} \frac{B_{j}(x)}{j !}\left(f^{j-1}(1)-f^{j-1}(0)\right) \\
R_{N}[f](x)=\frac{-1}{N !} \int_{0}^{1} B_{N}^{*}(x-t) f^{N}(t) d t
\end{gathered}
$$

where $\mathrm{B}_{\mathrm{N}}^{*}(\mathrm{x})=\mathrm{B}_{\mathrm{N}}(\mathrm{x}-[\mathrm{x}])$ and $[\mathrm{x}]$ denotes the largest integer not greater than $\mathrm{x}$.

Proof. See [1]. It is clear that the algebraic degree of exactness of the operator $P_{N}[$.$] is$ N.

Theorem 6.2. Suppose $f(x) \in C^{\infty}[0,1]$ and $P_{N}[f](x)$ is the approximate polynomial using Bernoulli method. Then the error bound would be obtained as follows

$$
\| \operatorname{error}\left(\mathrm{f}(\mathrm{x}) \|_{\infty} \leq \frac{1}{\mathrm{~N} !} \mathrm{B}_{\mathrm{N}} \mathrm{f}_{\mathrm{N}}\right.
$$

where $B_{N}$ and $F_{N}$ denote the maximum value of $B_{N}(x)$ and $f_{N}(x)$ in the interval $[0,1]$, respectively.

Proof. By considering $R_{N}[f](x)=\frac{-1}{m !} \int_{0}^{1} B_{N}^{*}(x-s) f^{N}(s) d x$ the proof is clear. 
Theorem 6.3. Suppose $k(x, s)$ be a smooth enough function and $P_{N}[k](x, s)$ is the approximate polynomial using Bernoulli method. Then the error bound would be obtained as follows

$$
\| \operatorname{error}\left(\mathrm{k}(\mathrm{x}, \mathrm{s}) \| \leq \frac{1}{(\mathrm{~N} !)^{2}} \mathrm{~B}_{\mathrm{N}}^{2} \mathrm{k}_{\mathrm{N}, \mathrm{N}}\right.
$$

where $\mathrm{B}_{\mathrm{N}}$ and $\mathrm{k}_{\mathrm{N}, \mathrm{N}}$ denote the maximum value of $\mathrm{B}_{\mathrm{N}}(\mathrm{x})$ and $\mathrm{k}^{\mathrm{N}, \mathrm{N}}(\mathrm{x}, \mathrm{s})$ in the interval $[0,1]$ respectively.

Theorem 6.4. We have Considered $\mathrm{m}=0$ and $\mathrm{c}_{0}=1$ in Eq. (1). Also assume that $\mathrm{y}(\mathrm{x})$ is the exact solution and $\mathrm{y}_{\mathrm{N}}(\mathrm{x})$ is the approximated solutions of (1) with the proposed assumption.

futrhurmore, we consider the following hypotheses

1) $\|\mathrm{y}(\mathrm{x})\| \leq \tilde{\mathrm{y}}, \forall \mathrm{x} \in \mathrm{I}=[0,1]$

2) $\|\mathrm{k}(\mathrm{x}, \mathrm{s})\|_{\infty} \leq \tilde{\mathrm{k}}, \forall(\mathrm{x}, \mathrm{s}) \in \mathrm{I} \times \mathrm{I}$

3) $\tilde{\mathrm{k}}+\mathrm{e}(\mathrm{k})<1$

Then

$$
\left\|y(x)-y_{N}(x)\right\|_{\infty} \leq \frac{e(f)+e(k) \tilde{y}}{(1-(\tilde{k}+e(k))}
$$

Where

$$
\begin{gathered}
e(k)=\| \operatorname{error}\left(k(x, s)\left\|_{\infty}=\right\| k(x, s)-k_{N}(x, s) \|_{\infty}, \forall(x, s) \in I \times I\right. \\
e(f)=\| \operatorname{error}\left(f(x)\left\|_{\infty}=\right\| f(x)-f_{N}(x) \|_{\infty}\right.
\end{gathered}
$$

Proof. Because both of the kernel $\mathrm{k}(\mathrm{x}, \mathrm{s})$ and function $\mathrm{f}(\mathrm{x})$ are approximated by

Bernoulli polynomials, then the obtained solution is an approximated polynomial in the form of $y_{N}(x)$. Our goal is to get an upper bound for the associated error between the exact solution $\mathrm{y}(\mathrm{x})$ and the approximated solution $\mathrm{y}_{\mathrm{N}}(\mathrm{x})$ for the Eq. (1). We have

$$
\begin{gathered}
\left\|y(x)-y_{N}(x)\right\|_{\infty}=\left\|f(x)+\int_{0}^{x} k(x, s) y(s) d s-f_{N}(x)-\int_{0}^{x} k_{N}(x, s) y_{N}(s) d s\right\|_{\infty} \\
\leq\left\|f(x)-f_{N}(x)\right\|_{\infty}+\left\|k(x, s) y(s)-k_{N}(x, s) y_{N}(s)\right\|_{\infty}
\end{gathered}
$$

on the other hand

$$
\begin{aligned}
\| \mathrm{k}(\mathrm{x}, \mathrm{s}) \mathrm{y}(\mathrm{s})- & \mathrm{k}_{\mathrm{N}}(\mathrm{x}, \mathrm{s}) \mathrm{y}_{\mathrm{N}}(\mathrm{s}) \|_{\infty} \\
& =\left\|\mathrm{k}(\mathrm{x}, \mathrm{s}) \mathrm{y}(\mathrm{s})-\mathrm{k}(\mathrm{x}, \mathrm{s}) \mathrm{y}_{\mathrm{N}}(\mathrm{s})+\mathrm{k}(\mathrm{x}, \mathrm{s}) \mathrm{y}_{\mathrm{N}}(\mathrm{s})-\mathrm{k}_{\mathrm{N}}(\mathrm{x}, \mathrm{s}) \mathrm{y}_{\mathrm{N}}(\mathrm{s})\right\|_{\infty} \\
\leq & \|\mathrm{k}(\mathrm{x}, \mathrm{s})\|\left\|\mathrm{y}(\mathrm{s})-\mathrm{y}_{\mathrm{N}}(\mathrm{s})\right\|_{\infty}+\left\|\mathrm{k}(\mathrm{x}, \mathrm{s})-\mathrm{k}_{\mathrm{N}}(\mathrm{x}, \mathrm{s})\right\|_{\infty}\left(\|\mathrm{y}(\mathrm{s})\|_{\infty}\right.
\end{aligned}
$$




$$
\begin{gathered}
+\left\|y(s)-y_{N}(s)\right\|_{\infty} \\
\leq(\tilde{k}+e(k))\left\|y(s)-y_{N}(s)\right\|_{\infty}+e(k) \tilde{y}
\end{gathered}
$$

from(21), (22)

$$
\left\|y(x)-y_{N}(x)\right\| \leq(e(f)+\tilde{k}+e(k))\left\|y(s)-y_{N}(s)\right\|_{\infty}+e(k) \tilde{y}
$$

therefore

$$
\left\|y(x)-y_{N}(x)\right\| \leq \frac{e(f)+e(k) \tilde{y}}{1-(\tilde{k}+e(k))}
$$

\section{Computational Complexity}

In this section, we will use the $\mathrm{O}$ notation to describe the time complexity of algorithms used in the method. For this purpose, we divided them into three categories. First, the algorithm of producing Bernouli vector, so producing each vector of Eq. (7) requiers $O(N+1)$, second, the time complexity of the algorithm of collocation of the nodes defined in Eq. (19), is $O(N+1)$, and finally, a single solution of linear system of Eq. (18) can be obtained with $O\left((N+1)^{2}\right)$ time complexity.

\section{Illustrative Examples}

To asses the performance of the proposed method, and show the efficiency of this method, we consider three illustrations of Volterra integro-differential equations with the initial conditions. The absolute errors for $\mathrm{K}$ different values are shown in Tables.The RMS error in the solutions:

$$
E=\sqrt{\frac{1}{\mathrm{k}} \sum_{\mathrm{i}=0}^{\mathrm{K}}\left(\mathrm{y}_{\mathrm{e}}\left(\mathrm{x}_{\mathrm{i}}\right)-\mathrm{y}\left(\mathrm{x}_{\mathrm{i}}\right)\right)^{2}}
$$

is obtained where $y\left(x_{i}\right)$ is the exact solution and $y_{e}\left(x_{i}\right)$ is the approximated solution of integral equation. Examples implemented by Matlab software.

Example 7.1. We consider the following Volterra integro- differential equation of forth order

$$
y^{\prime \prime \prime}(x)-y(x)=x\left(1+e^{x}\right)+3 e^{x}-\int_{0}^{x} y(s) d s, \quad 0 \leq x \leq 1
$$


with initial condition $y(0)=1, \mathrm{y}^{\prime}(0)=1, \mathrm{y}^{\prime \prime}(0)=2, \mathrm{y}^{\prime \prime \prime}(0)=3$ and the exact solution is $\mathrm{y}(\mathrm{x})=1+\mathrm{x} e^{x} \cdot[25]$

Solution. To solve this example, we approximate $\mathrm{y}^{\prime \prime \prime \prime}(\mathrm{x})$ by the Bernouli polynomials of order $\mathrm{N}$ as

$$
\mathrm{y}^{\prime \prime \prime}(\mathrm{x})=\mathrm{A}_{4}^{\mathrm{T}} \mathrm{B}(\mathrm{x})
$$

And, by using initial conditions of Eq. (23) and the operational matrix of integration (15), we have:

$$
\mathrm{y}(\mathrm{x})=\mathrm{A}_{4}^{\mathrm{T}} \mathrm{P}^{4} \mathrm{~B}(\mathrm{x})+\mathrm{A}_{3}^{\mathrm{T}} \mathrm{P}^{3} \mathrm{~B}(\mathrm{x})+\mathrm{A}_{2}^{\mathrm{T}} \mathrm{P}^{2} \mathrm{~B}(\mathrm{x})+\mathrm{A}_{1}^{\mathrm{T}} \mathrm{PB}(\mathrm{x})+\mathrm{A}_{0}^{\mathrm{T}} \mathrm{B}(\mathrm{x})
$$

which

$$
\mathrm{A}_{3}^{\mathrm{T}}=\left[\begin{array}{lllll}
3 & 0 & 0 & 0 & 0
\end{array}\right], \mathrm{A}_{2}{ }^{\mathrm{T}}=\left[\begin{array}{lllll}
2 & 0 & 0 & 0 & 0
\end{array}\right], \mathrm{A}_{1}{ }^{\mathrm{T}}=\left[\begin{array}{lllll}
1 & 0 & 0 & 0 & 0
\end{array}\right], \mathrm{A}_{0}{ }^{\mathrm{T}}=\left[\begin{array}{lllll}
1 & 0 & 0 & 0 & 0
\end{array}\right]
$$

Now, we approximate $\mathrm{f}(\mathrm{x})$ and $\mathrm{k}(\mathrm{x}, \mathrm{s})$ by Bernouli polynomials as stated in section 5 , by replacing these approximations and (24) in the (23) and by collocation points

$$
\mathrm{t}_{\mathrm{i}}=\frac{2 \mathrm{i}-1}{2(\mathrm{~N}+1)}
$$

we solve the linear algebric equation and achieve $\mathrm{A}_{4}$ vector. The comparison between the absolute error of presented method by $\mathrm{N}=4$ and $\mathrm{N}=8$, and legendre method are shown in Table 1which shows Bernouli matrix method is more accurate and also, it can be seen with increasing $\mathrm{N}$, error reduces. and the error corresponds with the upper bound error in theorem 6.3.

Table 1. Absolute error for example 1

\begin{tabular}{|l|l|l|l|}
\hline \multicolumn{1}{|c|}{$\mathrm{x}_{\mathrm{i}}$} & \multicolumn{1}{|c|}{$\begin{array}{c}\mathrm{e}(\mathrm{xi}) \\
\text { (present Method,N=4) }\end{array}$} & $\begin{array}{c}\mathrm{e}(\mathrm{xi}) \\
\text { (present method, N=8) }\end{array}$ & $\begin{array}{c}\mathrm{e}(\mathrm{xi}) \\
\text { (legendre method)[25] }\end{array}$ \\
\hline 0.0 & $3.0000 \mathrm{e}-004$ & 0.0000 & 0.0000 \\
\hline 0.2 & $5.4322 \mathrm{e}-005$ & $7.7721 \mathrm{e}-005$ & $2.8055 \mathrm{e}-004$ \\
\hline 0.4 & $1.5088 \mathrm{e}-004$ & $3.0926 \mathrm{e}-005$ & $4.7299 \mathrm{e}-004$ \\
\hline 0.6 & $4.4686 \mathrm{e}-004$ & $6.0544 \mathrm{e}-004$ & $2.5270 \mathrm{e}-002$ \\
\hline 0.8 & $2.2000 \mathrm{e}-003$ & $4.1000 \mathrm{e}-003$ & $8.4430 \mathrm{e}-002$ \\
\hline 1.0 & $5.6000 \mathrm{e}-003$ & $1.7700 \mathrm{e}-003$ & $2.1828 \mathrm{e}-002$ \\
\hline The RMS error & $5.6000 \mathrm{e}-003$ & $1.7700 \mathrm{e}-003$ & $2.1828 \mathrm{e}-002$ \\
\hline
\end{tabular}

Example 7.2. We consider the following Volterra integro-differential

$$
y^{\prime}(x)=1-\int_{0}^{x} y(s) d s, 0 \leq x<1,
$$

with initial condition $y(0)=0$ and the exact solution is $y(x)=\sin x$. [26]

Solution. To solve this example, we approximate $y^{\prime}(x)$ by the Bernouli polynomials of order $\mathrm{N}$, as 


$$
\mathrm{y}^{\prime}(\mathrm{x})=\mathrm{A}_{1}^{\mathrm{T}} \mathrm{B}(\mathrm{x})
$$

and, by using initial conditions of (25) and the operational matrix of integration (15), we have:

$$
y(x)=A_{1}^{T} P B(x)
$$

then, (25) can be rewritten as

$$
\begin{gathered}
A_{1}^{\mathrm{T}} \mathrm{B}(\mathrm{x})=\mathrm{F}^{\mathrm{T}} \mathrm{B}(\mathrm{x})-\mathrm{B}^{\mathrm{T}}(\mathrm{x}) \mathrm{KDP}^{\mathrm{T}} \mathrm{A}_{1}, \\
\text { where } \mathrm{F}^{\mathrm{T}}=\left[\begin{array}{lllll}
1 & 0 & 0 & 0 & 0
\end{array}\right], \mathrm{D}=\int_{0}^{\mathrm{x}} \mathrm{B}(\mathrm{s}) \mathrm{B}^{\mathrm{T}}(\mathrm{s}) \mathrm{ds}, \mathrm{K}=\left(\begin{array}{lllll}
1 & 0 & 0 & 0 & 0 \\
0 & 0 & 0 & 0 & 0 \\
0 & 0 & 0 & 0 & 0 \\
0 & 0 & 0 & 0 & 0 \\
0 & 0 & 0 & 0 & 0
\end{array}\right)
\end{gathered}
$$

we replace the collocation points into (28), then, we solve the linear algebric and achieve $A_{1}$ vector. The comparison between the results of presented method for $\mathrm{N}=4$ and $\mathrm{N}=6$, and Bessel series method are shown in Table2. The comparison between

\begin{tabular}{|c|c|c|c|}
\hline $\mathrm{x}_{\mathrm{i}}$ & $\begin{array}{c}\mathrm{e}(\mathrm{xi}) \\
\text { (present Method,N=4) }\end{array}$ & $\begin{array}{c}\mathrm{e}(\mathrm{xi}) \\
\text { (present method, } \mathrm{N}=6)\end{array}$ & $\begin{array}{c}\mathrm{e}(\mathrm{xi}) \\
\text { (Bessel series method)[26] }\end{array}$ \\
\hline 0.0 & $2.8620 \mathrm{e}-005$ & $6.4459 \mathrm{e}-006$ & 0.0000 \\
\hline 0.2 & $5.4422 \mathrm{e}-006$ & $3.4951 \mathrm{e}-007$ & $4.0240 \mathrm{e}-007$ \\
\hline 0.4 & $7.9628 \mathrm{e}-006$ & $1.7251 \mathrm{e}-007$ & $2.0574 \mathrm{e}-007$ \\
\hline 0.6 & $9.6856 \mathrm{e}-006$ & $3.5274 \mathrm{e}-007$ & $3.7576 \mathrm{e}-007$ \\
\hline 0.8 & $3.6086 \mathrm{e}-006$ & $5.2260 \mathrm{e}-007$ & $1.8172 \mathrm{e}-007$ \\
\hline 1.0 & $5.6000 \mathrm{e}-003$ & $5.2260 \mathrm{e}-007$ & $9.6665 \mathrm{e}-006$ \\
\hline The RMS error & $1.7372 \mathrm{e}-005$ & $1.3444 \mathrm{e}-006$ & $3.9543 \mathrm{e}-006$ \\
\hline
\end{tabular}
$\mathrm{N}=4$ and $\mathrm{N}=6$ confirms the findings of the first example and shows that by increasing $\mathrm{N}$ and consequently increasing the number of nodes, the error decreases.

Table 2. Absolute error for example 2

Example 7.3.We consider the following Volterra integro-differential equation

$$
y^{\prime}(x)+y(x)=\int_{0}^{x} e^{s-x} y(s) d s, \quad 0 \leq x<1
$$

with initial condition $y(0)=1$ and the exact solution is $y(x)=e^{-x} \cosh x$. [9]

Solution. To solve this example, we approximate $\mathrm{y}^{\prime}(\mathrm{x})$ by the Bernouli polynomials, as

$$
y^{\prime}(x)=A_{1}^{T} B(x)
$$

where, $A_{1}$ is the unknown vector. And, by using initial conditions of Eq. (29) and the operational matrix of integration Eq. (16), we have:

$$
y(x)=A_{1}^{\mathrm{T}} P B(x)+A_{0}^{\mathrm{T}} \mathrm{B}(\mathrm{x})
$$

which $A_{0}^{T}=\left[\begin{array}{lllll}1 & 0 & 0 & 0 & 0\end{array}\right]$ Now, by replacing(30), (31) in the (29), 


$$
A_{1}^{T} B(x)+A_{1}^{T} P B(x)+A_{0} B(x)=B^{T}(x) K D\left(A_{1}+P^{T} A_{1}\right)
$$

Now, by collocating points and solving the linear algebraic for $\mathrm{N}=4$ and $\mathrm{N}=6$ we achieve $A_{1}$ vector. The comparison between the absolute error of presented method, are shown in Table 3 and shows that by increasing $\mathrm{N}$ and consequently increasing the number of nodes, the error decreases

Table 3. Absolute error for example 2

\begin{tabular}{|l|l|l|}
\hline \multicolumn{1}{|c|}{$\mathrm{x}_{\mathrm{i}}$} & \multicolumn{1}{c|}{$\begin{array}{c}\mathrm{e}(\mathrm{xi}) \\
\text { (present Method,N=4) }\end{array}$} & $\begin{array}{c}\mathrm{e}(\mathrm{xi}) \\
\text { (present method, N=6) }\end{array}$ \\
\hline 0.0 & 0.0000 & 0.0000 \\
\hline 0.1 & $7.8212 \mathrm{e}-003$ & $3.2108 \mathrm{e}-004$ \\
\hline 0.2 & $1.1000 \mathrm{e}-003$ & $2.4000 \mathrm{e}-004$ \\
\hline 0.3 & $8.4639 \mathrm{e}-004$ & $7.9000 \mathrm{e}-004$ \\
\hline 0.4 & $8.5470 \mathrm{e}-003$ & $1.8000 \mathrm{e}-004$ \\
\hline 0.5 & $3.4000 \mathrm{e}-003$ & $3.3800 \mathrm{e}-003$ \\
\hline The RMS error & $4.9000 \mathrm{e}-003$ & $1.4000 \mathrm{e}-003$ \\
\hline
\end{tabular}

\section{Remark}

It is found that the errors in Bernoulli matrix method solutions get reduced in comparison with the errors in [26], [25]. The matrices D and P in Eqs (15), (28) have large numbers of zero elements and they are sparse, hence the present method is very attractive and reduces the CPU time and the computer memory. Also Theorem 6.4 shows the answer is convergent, and as shown in examples the error reduces with increasing $\mathrm{N}$.

\section{Conclusion}

In this article, we have shown that the Bernoulli matrix method can be employed to solve Volterra integro-differential equations. One of the advantage of this method is that the numerical solution of these equations can be converted into system of linear algebraic equations. The numerical results are used to demonstrate the application of this method. Considering the ease of working with high-order Bernoulli polynomials and the low error, This method is superior to other methods.

. It is only with some minor modifications that the proposed method can be extended to systems of Volterra integro-differential equations.

\section{References}

1. Abramowitz. M., Stegun I. A., "Handbook of Mathematical Functions with Formulas", Graphs, and Mathematical Tables, National Bureau of Standards, Wiley, New York (1972). 
2. Agoh T., Dilcher K., "Integrals of products of Bernoulli polynomials", J. Math. Anal. Appl. 381 (2011) 1016.

3. Arfken G., "Mathematical methods for physicists", third ed. San Diego, Academic press (1985).

4. Bhrawy A. H., Tohidi E., Soleymani F., "A new Bernoulli matrix method for solving high-order linear and nonlinear Fredholm integro-differential equations with piecewise intervals", Appl. Math. Comput. 219 (2012) 482-497.

5. Buric T., Elezovic N., "Bernoulli polynomials and asymptotic expansions of the quotient of gamma functions", J. Comput. Appl. Math. 235 (2011) 3315-3331.

6. Cheon G., "A note on the Bernoulli and Euler polynomials", Appl. Math. Lett. 16 (2003) 365368.

7. Costabile F., Dellaccio F., Gualtieri M. I., "A new approach to Bernoulli polynomials, Rendiconti di Matematica", Serie VII 26 (2006) 112.

8. Delves L. M., Mohamed J. L., "Computational Methods for Integral Equations", Cambridge University Press, London (1985).

9. Ebrahimia N., Rashidiniaa J., "Spline Collocation for Fredholm and Volterra Integro-Differential Equations", Int Journal of Math. Mod Comp. 4 (3) (2014) 289-298.

10. Gottlieb D., Hussaini M., Orszg S., "Theory and applications of spectral methods in spectral methods for partial differential equations", SIAM, Philadelphia (1984).

11. Kress R., "Linear Integral Equations", Springer-Verlag, Berlin (1989).

12. Kreyszig E., "Introductory Functional Analysis with Applications", John Wiley and Sons Press, New York (1978).

13. Kurt B., "A further generalization of the Bernoulli polynomials and on the 2d-Bernoulli Polynomials", Appl. Math. Sci. 4 (2010) 2315-2322.

14. Kurt B., Simsek Y., "Notes on generalization of the Bernoulli type polynomials", Appl. Math. Comput. 218 (2011) 906-911

15. Lu D., "Some properties of Bernoulli polynomials and their generalizations", Appl. Math. Lett. 24 (2011) 746-751.

16. Mashayekhi S., Ordokhani Y., Razzaghi M., "Hybrid functions approach for nonlinear constrained optimal control problems", Commun. Nonli. Sci. Numer. Simul. 17 (2012) 1831-1843.

17. Natalini P., Bernardini A., "A generalization of the Bernoulli polynomials", J. Appl. Math. 2003 (2003) 155-163.

18. Norlund N. E., "Vorlesungen uber Differenzenrechnung", Springer-Verlag, New York (1954).

19. Ordokhani Y., "An application of Walsh functions for Fredholm-Hammerstein integro-differential equations", Int. J. Contemp. Math. Sciences, Vol. 5 No. 22 (2010)1055-1063. 
20. Rad. J. A, Kazem. S, Shaban. M, Parand. K, A new operational matrix based on Bernouli polynomials, (2014) arXiv:1408.2207v1 [cs.NA].

21. Rahimkhani.P, Ordokhani. Y, Babolian. E, ]. Fractional-order Bernoulli wavelets and their applications, Applied Mathematical Modelling,Vol. 40 (2016) 8087-8107.

22. Tohidi. E, Bhrawy. A. H, Erfani. K, A collocation method based on Bernoulli operational matrix for numerical solution of generalized pantograph equation, Appl. Math. Mod. 37(6) (2012) 4283-4294.

23. Toutounian. F, Tohidi. E, Shateyi. S, A collocation method based on the Bernoulli operational matrix for solving high-order linear complex differential equations in a rectangular domain, Abst. Appl. Anal., Hindawi Pub. Co. 2013 (2013) 1-12.

24. Vandiver. H, Certain congruences involving the Bernoulli numbers, Duke Mathematical Journal 5 (1939) 548-551.

25. Venkatesh. S. G, Ayyaswamy. S. K, Raja Balachandar. S, Legendre approximation solution for a class of higher-order Volterra integro-differential equations, Ain Shams Engineering Journal, 3 (2012) 417-422.

26. Yusbasi. S, Sahin. N, Yildrim. A, A collocation approach for solving high-order linear FredholmVolterra integro-differential equations, Math. Comput. Model. 55 (2012), 547-563. 